\title{
Differences between the QBO in the first and in the second half of the ERA-40 reanalysis
}

\author{
H. J. Punge ${ }^{1,2}$ and M. A. Giorgetta ${ }^{1}$ \\ ${ }^{1}$ Max Planck Institute for Meteorology, Bundesstr. 53, 20146 Hamburg, Germany \\ ${ }^{2}$ IMPRS on Earth System Modelling, Bundesstr. 53, 20146 Hamburg, Germany
}

Received: 4 September 2006 - Published in Atmos. Chem. Phys. Discuss.: 26 September 2006

Revised: 12 January 2007 - Accepted: 30 January 2007 - Published: 7 February 2007

\begin{abstract}
The representation of the quasi-biennial oscillation $(\mathrm{QBO})$ is investigated in the ERA-40 reanalysis. In the lower stratosphere, where there are a reasonable number of observations, the representation of the QBO is equally good throughout the record. However, strong differences between the first and the second half of the zonal wind data set are found in the upper stratosphere, with a typical offset of $10 \mathrm{~m} / \mathrm{s}$ in the equatorial zonal wind in the earlier part versus the later part of the ERA-40 record. At the same time, the strength of the QBO is similar. The 7-year running means of zonal wind, wind shear and temperature reveal interesting structures with major changes occuring in the beginning and the middle of the 1980s. Possible explanations are discussed. The identified change of the reanalysed wind profiles over time in ERA-40 demands for a careful use of equatorial upper stratospheric winds from the reanalysis e.g. for model validation purposes.
\end{abstract}

\section{Introduction}

Present-day reanalyses include observations over several decades in a rather consistent manner. Dynamic modes like El Nino-Southern oscillation (ENSO), North Atlantic Oscillation (NAO) or the quasi-biennial oscillation (QBO) are represented with remarkable accuracy. For the QBO of zonal wind, the present study confirms this statement for the lower stratosphere, showing a continuous signal over the course of the ERA-40 reanalysis (Uppala et al., 2005). In the upper stratosphere, however, the early and late portions of the data set differ significantly.

Unfortunately, the number of QBO cycles in the timeseries available from reanalysis is limited. More or less continuous observations of the QBO domain in the stratosphere ex-

Correspondence to: $\mathrm{H}$. J. Punge

(heinzjuergen.punge@zmaw.de) ist only since the 1950s. For this reason, it is very difficult to make statistically sound statements. Also, this work does not include a detailed comparison to observational data records on the QBO, as it has already been presented in the literature (Baldwin and Gray, 2005; Uppala et al., 2004). Rather, the purpose of this work is to illustrate the change in the upper stratospheric conditions and the QBO using two 20 year sections of zonal wind data. It should be noted that there is another useful way to study the QBO and its variability by use of climate models that recently managed to simulate a realistic QBO, see Takahashi (1996) or Giorgetta et al. (2006) for instance.

The European Centre for Medium-Range Weather Forecasts (ECMWF) has used a recent version of its forecast model to prepare the long time reanalysis ERA-40. It is based on a wide range of observation data, accumulated from ground stations, aircraft measurements and satellites. However, the kind and number of observations vary strongly during 1957 to 2002, the time range of the reanalysis (Uppala et al., 2004). A study on sensitivity of ERA-40 on the observing system was performed by Bengtsson et al. (2004). Their work shows that the representation of the QBO depends crucially on the assimilation of winds from radiosonde records and can not be achieved using satellite data alone. In the reanalysis system, the atmosphere is covered up to an altitude of $0.1 \mathrm{hPa}$ with a good vertical resolution of $60 \mathrm{lev}$ els. Therefore one can expect a fair representation also of the stratosphere. However, care needs to be taken because observations are sparse at high altitudes. We want to look at variability on the interannual scale, so it is sufficient to use monthly means of the 6-hourly ERA-40 data set for our work.

A realistic representation of the QBO in ERA- 40 has been reported in previous publications on this topic, e.g. in Baldwin and Gray (2005), Pascoe et al. (2005) and Randel et al. (2004). The QBO timeseries of zonal wind in ERA-40 presented in the literature (Uppala et al., 2004, see Fig. 12

Published by Copernicus GmbH on behalf of the European Geosciences Union. 
therein) and the remarks of Giorgetta et al. (2006) motivated a closer look at possible long term variations in the QBO amplitude. We choose a composite approach to study this question. The ERA-40 record is split to reveal a possible difference between its earlier and later years, and to still have a comparable number of cycles in each composite. Some details of the composite are highlighted and the magnitude of the difference in the QBO is compared to the one in the annual cycle.

In the second part, a more detailed picture of the underlying variability is aimed at. Possible explanations for the observed differences are sought after by studying wind and temperature fields on a time scale of 7 years in order to detect the timing of when the change occurred while the QBO signal itself is mostly eliminated. A brief discussion of implications of the findings concludes this work.

\section{Methods}

Composites are a common tool for analyzing periodic signals. Given a time series of data, one chooses a reference value and marks all points in time when the time series is rising above (or alternatively falling below) this selected reference value. The composite is then computed as the average of all partial timeseries centered around the identified points in time. This composite shows the typical time evolution in the selected time frame with respect to the time when the reference value occurs. Uncertainty in the evolution increases by construction from the point of reference to larger time lags before or after this point, and also with increasing spatial distance to this point.

This method is applied routinely (Giorgetta et al., 2006), for QBO signals, where usually the transition from easterlies to westerlies or vice versa is chosen as reference value. Difficulties can arise when the number of nodes varies among the levels, which is why this method is feasible only in regions where the QBO is the dominant mode of variability.

For our purposes it is adequate to neglect the latitude dependence of the QBO amplitude, as it is approximately Gaussian around the equator where the QBO is driven (Holton and Lindzen, 1972; Baldwin et al., 2001). Thus, $+/-5^{\circ}$ latitudinal averages are used throughout this work, accounting for the core zone of the QBO. The QBO amplitudes mentioned here will therefore be slightly smaller than the amplitudes observed directly at the equator. Furthermore, for the composites, we substract the climatological annual variability but retain the annual mean, so that the filtered data still contain the characteristic asymmetries between westerly and easterly jets.

Unfortunately the zonal wind time series are not strictly monotonic around the east-west/west-east transitions even in the QBO core region between 10 and $50 \mathrm{hPa}$ where the signal is most prominent. Some cycles show delays or short reversals on the order of few months. This can lead to additional, artificial partial time series in the construction of composites which distort the result. One solution to this problem would be to compute the composites from smoothed, e.g. 5 month averaged time series. Instead, we decided to construct our composites only at one level at the upper end of the QBO core region, and to check the partial time series manually. The $10 \mathrm{hPa}$ level was chosen because in this work the focus is on the upper stratosphere where observations are sparse and therefore discrepancies are likely to occur. The closer the construction level is to the region of interest, the more accurate are the composites. If there are several transitions of zero zonal wind close to each other due to a reversal as described above, we select only the first one of them for the composites as it appears to suit best for depicting the QBO evolution before and thereby above the transition, as the QBO generally propagates downward.

To estimate the evolution of the QBO amplitude we use the method presented by Baldwin and Gray (2005). In brief, they show that if a reference QBO area at the equator between 70 and $10 \mathrm{hPa}$ is selected, one can compute the amplitude of the signal at any position in the atmosphere simply by taking the product of the best correlation to a level within the reference area and the variance at this position. This is valid if the QBO contribution at that position is perfectly correlated to the corresponding reference series. We apply this method to find QBO amplitudes at altitudes above $10 \mathrm{hPa}$. By defining 7-year time series within the full data set we can get the time evolution of the (7-year based) QBO amplitude. Seven year periods seem appropriate for analyzing a $\approx 28$-month phenomenon - this way, shorter term variations are averaged over, but long term trends are retained. However, one should note that the method applied here may overestimate the actual QBO amplitude if the underlying assumptions do not apply completely, as stated by Pascoe et al. (2005).

\section{Results}

Composites of zonal wind in time and altitude, taken at the transition from easterlies to westerlies at $10 \mathrm{hPa}$, are shown in Fig. 1. Composites are displayed for the whole ERA-40 record (a) and partial records 1960 to 1979 (b) and 1980 to 1999 (c).

For all three composites, the QBO period is about 27 months, the peak-to-peak amplitude reaches 45 to $50 \mathrm{~m} / \mathrm{s}$ and the velocity of vertical propagation is similar. Furthermore, all composites feature some typical characteristics of the QBO, including stronger easterlies than westerlies, westerlies persisting longer in the lower part of the QBO regime, and rapid decrease of the amplitude below $70 \mathrm{hPa}$. At the top of the QBO domain, however, the composites differ from each other.

Significant differences occur for the two 20-year time frames used for Figs. $1 \mathrm{~b}$ and c. Between 2 and $10 \mathrm{hPa}$ in the upper stratosphere, an easterly anomaly in zonal wind 

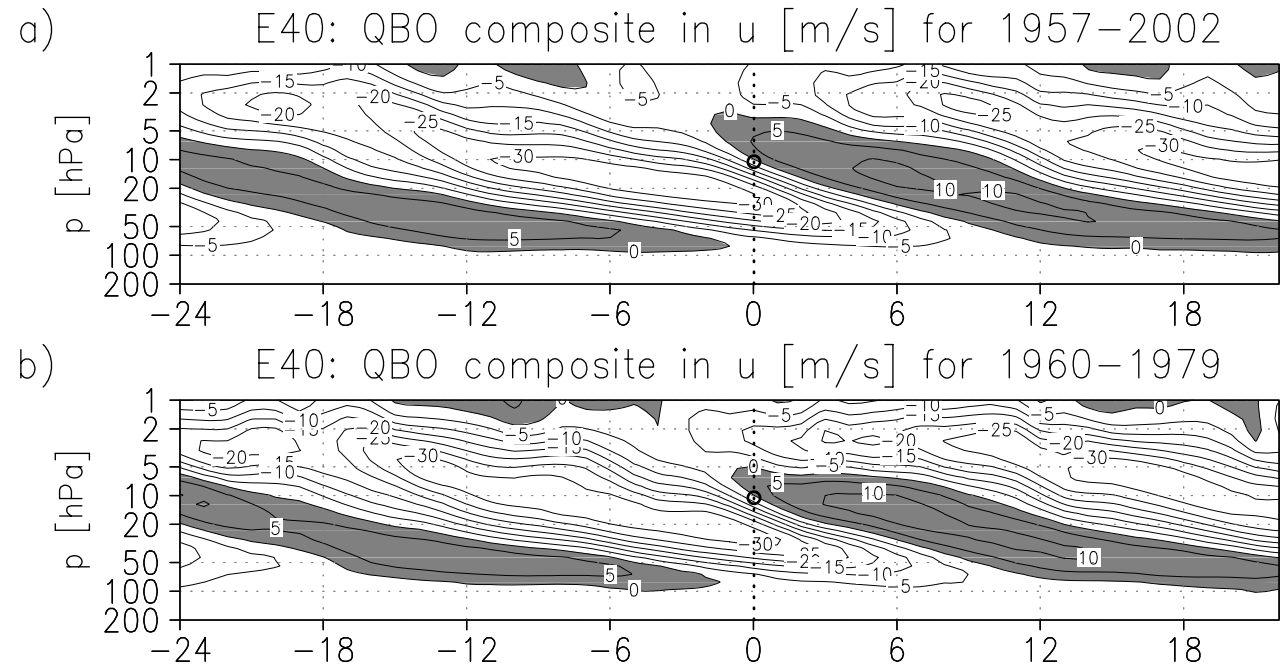

c)

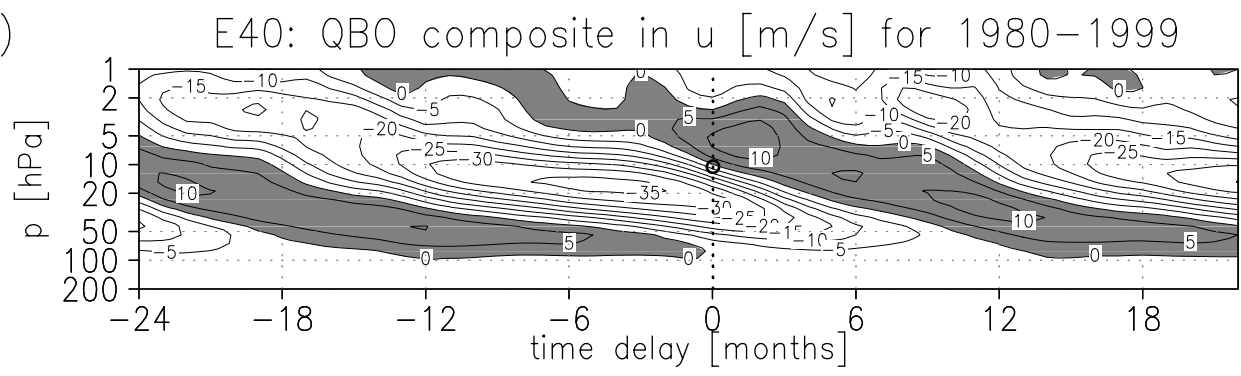

Fig. 1. Composites of the zonal wind QBO in the equatorial stratosphere of the ERA-40 reanalysis, taken at the transition from easterlies to weaterlies. The transition at the $10 \mathrm{hPa}$ level at zero time delay. Composites are computed for (a) the full data set (September 1957-August 2002), (b) January 1960-December 1979 and (c) January 1980-December 1999.

is observed in the early years when compared to the later period. At lower levels, below $10 \mathrm{hPa}$, the two composites agree quite well, considering that only 7 and 6 QBO cycles were used for the construction, respectively. To further illustrate the differences we present cross sections through the composite in Figs. 2 and 3.

Figure 2 displays the state of the QBO at transition from easterlies to westerlies and from westerlies to easterlies at 10 $\mathrm{hPa}$. For both composite types, the difference between the early and late periods of ERA-40 is obvious. The differences are strongest between 7 and $2 \mathrm{hPa}$. Above, it tends to reverse, but one has to keep in mind that there may be some difference in phase among the composites at these levels and that the QBO amplitude becomes small. Below $10 \mathrm{hPa}$, the differences are small for both kinds of composites, i.e. smaller than $10 \%$ of the amplitude. For the transition to easterlies, there seems to be a slight phase difference between the two composites, potentially distorting the construction of composites to a small amount.

Figure 3 shows the evolution of the QBO at $4.2 \mathrm{hPa}$. The difference between the two periods amounts to up to $25 \mathrm{~m} / \mathrm{s}$. Note that the signals are relatively noisy, as the semiannual oscillation is quite strong at these levels and does not cancel entirely for the 20 year periods, indicating that the removal of the annual signal was not complete. Indeed, Figure 1c shows some residual 6-month signal. This is related to an alignment of QBO and SAO in the second 20-year record. The transition to westerlies at $10 \mathrm{hPa}$ occurs in the same month in 4 out of 9 cases there. As the SAO also changed during this time span, we see the residual signal in the composite. We conclude from this figure that the difference does not seem to depend on the phase of the QBO in a simple manner.

To confirm the difference between the two 20-year periods, the respective average zonal mean zonal wind is computed. Both profiles are shown in Fig. 4a, together with their difference. For both time periods, the average zonal wind is similar up to $15 \mathrm{hPa}$. It is easterly in the troposphere, approaches zero in the lower stratosphere around $70 \mathrm{hPa}$ and is easterly above. Above the $15 \mathrm{hPa}$ level, at which the mean zonal wind is $-12 \mathrm{~m} / \mathrm{s}$, the earlier period has much stronger easterly winds than the later one. At $4 \mathrm{hPa}$, the difference reaches a maximum of more than $8 \mathrm{~m} / \mathrm{s}$. At the top of the stratosphere, the averages approach each other again and are equal at $1 \mathrm{hPa}$, being easterly at about $5 \mathrm{~m} / \mathrm{s}$. A student t-test shows that the difference between the two periods is significant at the $95 \%$ confidence level between 7 and $2 \mathrm{hPa}$. 


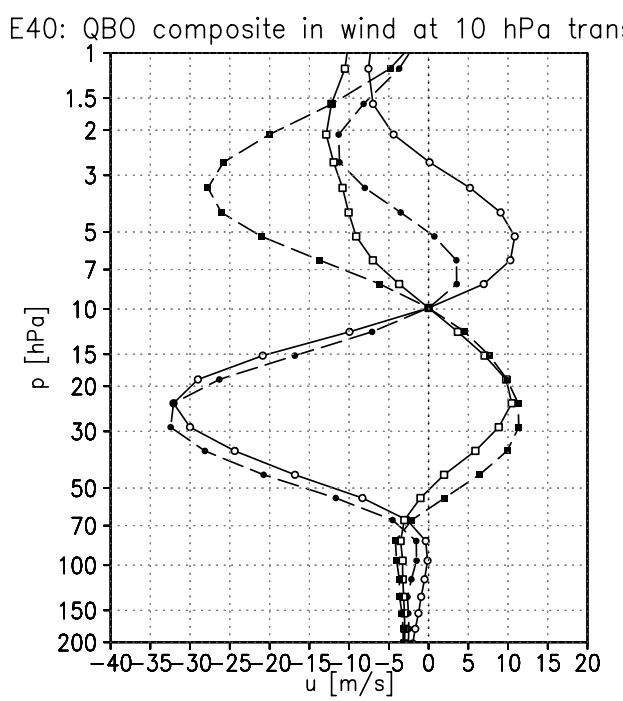

Fig. 2. Composites of the zonal wind QBO of the ERA-40 reanalysis, at the time of east-west and west-east transitions at $10 \mathrm{hPa}$. Solid, open circles: 1980-1999 composite east to west; dashed, filled circles: 1960-1979 composite east to west; solid, open squares: 1980-1999 composite west to east; dashed, filled squares: 1960-1979 composite west to east.

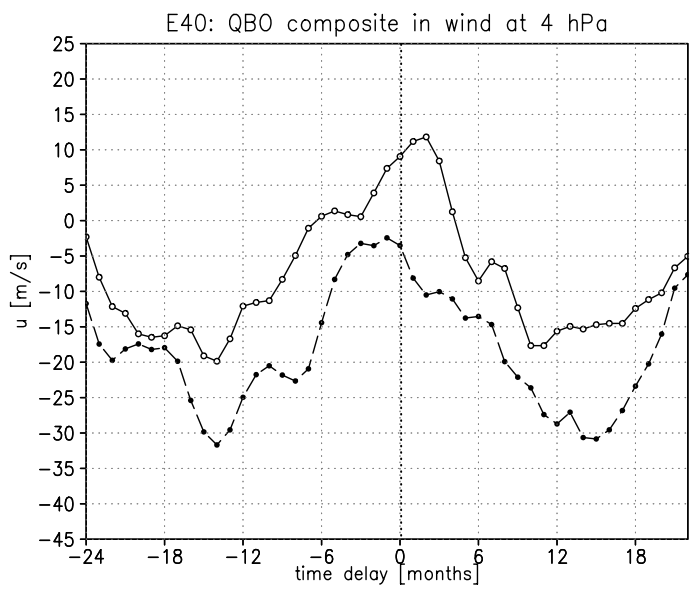

Fig. 3. Composites of the zonal wind QBO of the ERA-40 reanalysis as in Fig. 1, only at the 4.2 hPa level. Solid: 1980-1999 composite, dashed: 1960-1979.

Figure $4 \mathrm{~b}$ shows the peak-to-peak range of the QBO signal, i.e. the difference between the maximum easterlies and westerlies at each level, in the two 20-year composites of Figs. $1 \mathrm{~b}$ and $\mathrm{c}$ and their difference. The Figure shows that the strength of the QBO is quite similar at the beginning and the end of the ERA-40 record. In the lower stratosphere, the QBO signal in the earlier period is stronger by about $5 \mathrm{~m} / \mathrm{s}$. At about $5 \mathrm{hPa}$, this reverses and the QBO of the later time period is stronger by about the same amount. Since the com- posites consist of only a small number of QBO cycles, these differences are not significant in the sense of a student $t$ test, and so they can not be distinguished from the natural variability of the cycles.

Figure 4 illustrates that it is the change in the climatology that causes the difference in the QBO composites, while the strength of the QBO remains almost constant.

To further investigate the timing and origin of the observed changes, we compute running means of zonal wind and temperature through the course of the reanalysis record. 7-year running means are taken to cover 7 annual and about 3 QBO cycles, and thereby mostly eliminate these two modes. Figure $5 \mathrm{a}$ shows the change in zonal mean zonal wind over the course of ERA-40 in the equatorial stratosphere. Some residual QBO is left in Fig. 5a, e.g. in between 50 and $20 \mathrm{hPa}$ around 1985. This happens at times of misrepresentation of easterly and westerly QBO phases in the 7-year period, which can occur because of the variable duration of the individual QBO phases.

In the lower stratosphere, average winds are about zero and constant throughout the record. Between 10 and $20 \mathrm{hPa}$, there is a phase of stronger easterly winds between 1983 and 1989 and less easterly winds in some years like 1973, 1996 and 1970. No general trend is found, consistent with Fig. 4a. Higher up, between 7 and $2 \mathrm{hPa}$, average winds are strongly easterly at $-16 \mathrm{~m} / \mathrm{s}$ until 1979 , less easterly at $-12 \mathrm{~m} / \mathrm{s}$ until about 1983, and show a further westerly trend towards the 1990s, where about $-4 \mathrm{~m} / \mathrm{s}$ are recorded between 1989 and 1995. Thereafter, winds become slightly more easterly again.

Figure 5b shows the QBO peak-to-peak amplitude in zonal wind. Here, the QBO peak-to-peak amplitude was estimated using the method of Baldwin and Gray (2005). Because amplitudes were computed over 7-year periods some smoothing is involved. The QBO maximum occurs between 10 and $20 \mathrm{hPa}$. Relative to the other years, it is shifted downward slightly in the years around 1980. The amplitude of the maximum is reduced during the 1970s and towards the end of the record. In the upper stratosphere, we find a maximum around 1989 , where the amplitude is increased by $50 \%$ compared to its average value at $4 \mathrm{hPa}$. A similar increase appears at the very end of the record.

Figure $5 \mathrm{c}$ shows the 7-year running mean temperature, where the overall mean of 1957-2002 was substracted. Above $7 \mathrm{hPa}$, there is a warm period in the mid-1970s and a cooling trend after 1983 .

The QBO amplitude in temperature anomaly given in Fig. $5 \mathrm{~d}$ also has some interesting aspects. At $70 \mathrm{hPa}$, there is a decrease after 1983, while at $30 \mathrm{hPa}$, the amplitude was increased in the 1990s. Between 10 and $5 \mathrm{hPa}$, the amplitude is larger in the second part of ERA- 40 compared to the first one, while the reverse is true above. There is virtually no QBO signal in temperature between 2 and $3 \mathrm{hPa}$ during 1983-1988.

Figure 6 reveals that the changes in the 7-year mean displayed in Figs. 5a and $\mathrm{c}$ did not occur uniformly in all 
a)

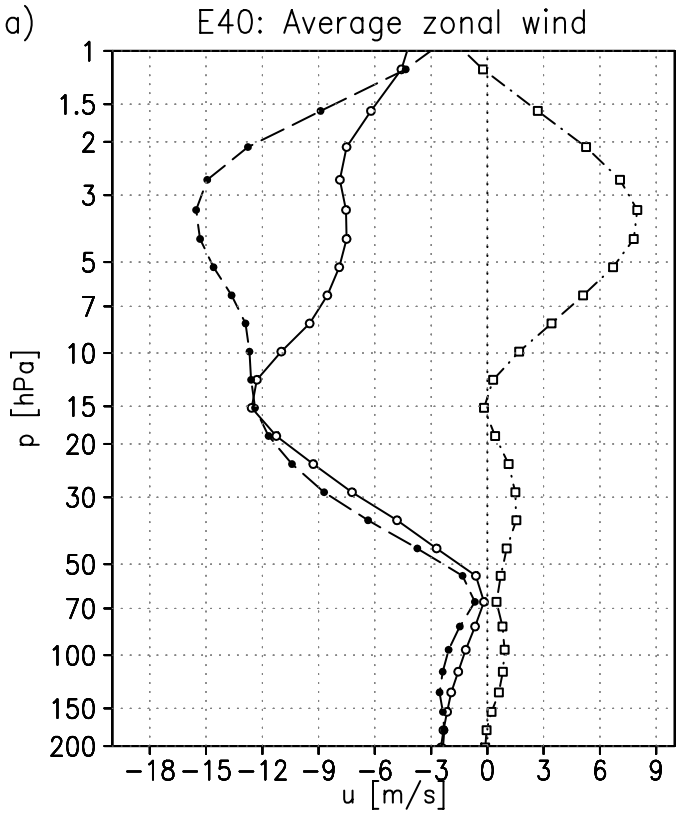

b) E40: QBO peak-to-peak amplitude

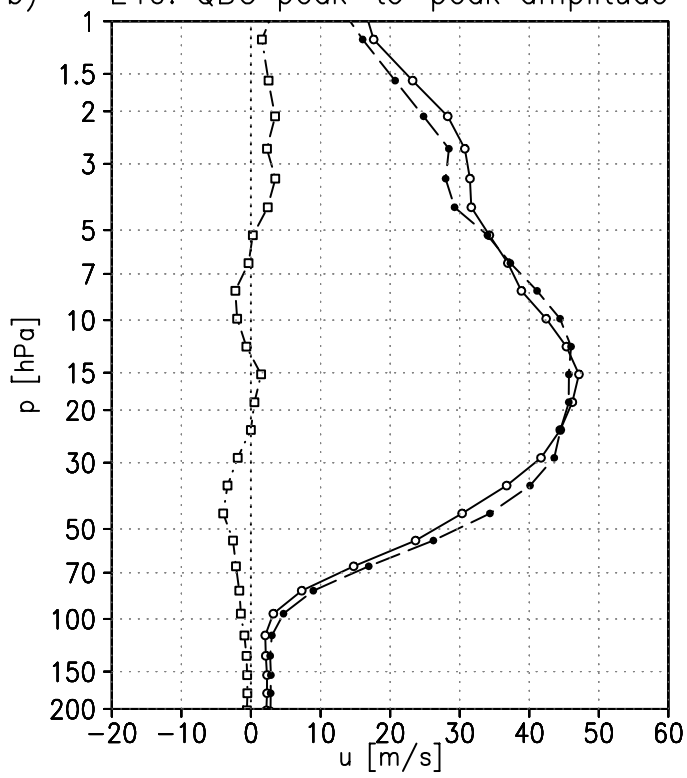

Fig. 4. (a) Long-dashed: Annual mean equatorial zonal wind of the 1960-1979 period; solid: Same for the 1980-1999 period; dot-dashed: difference between the two periods. (b) QBO peak-to-peak range in the composites of Fig. 1; long-dashed: 1960-1979 period, cf. Fig. 1b; solid: 1980-1999 period, cf. Fig. 1c; dot-dashed: difference between the two periods. Note the different scales at the abscissae of the two panels.

seasons. January and June were selected because they show the most pronounced changes. 7-year averaged anomalies from the 45-year climatological mean are displayed for both zonal wind ( $a$ and $c$ ) and temperature (b and d). In June zonal wind, shown in Fig. 6b, two domains are clearly visible above $7 \mathrm{hPa}$, with a transition from easterly to more westerly conditions starting in about 1977 at $5 \mathrm{hPa}$ and reaching $1 \mathrm{hPa}$ by 1982 . The difference is strongest at $2 \mathrm{hPa}$ and amounts to $30 \mathrm{~m} / \mathrm{s}$ between the 1970-1975 and 1985-1990 periods. For January, shown in Fig. 6a, the evolution is distinctly different. Two domains are also found between 10 and $2 \mathrm{hPa}$, but the transition towards more westerly winds occurs between 1983 and 1985 here. In the earlier part, there is a trend for the anomaly to move upward from about 6 to $3 \mathrm{hPa}$ and strengthen. Furthermore, there are two domains with a reversed change from westerly to easterly between 2 and $1 \mathrm{hPa}$.

The change in the temperature for June in Fig. 6d is a bit less distinct than in the annual running mean, but shows the same features; they extend downward a bit further. January temperatures in Fig. 6c, however, show a very distinct anomaly similar in shape to the corresponding zonal wind anomaly. High temperature anomalies occur at times of more westerly wind shear in the first part and cold anomalies in the more easterly wind shear later on, consistent with thermal wind balance, which shall to be discussed in the next paragraph.

An expression for the relation of vertical wind shear and meridional temperature gradient in the equatorial $\beta$-plane was given by Baldwin et al. (2001). We check for this relationship in the ERA-40 record. The result is given in Fig. 7. The wind shear reflects the changes that were found in the wind field. As Fig. 7a shows, negative shear dominates above $3 \mathrm{hPa}$ until 1983 , while mostly positive shear is found between 3 and $10 \mathrm{hPa}$. After 1983, shear is negative between 15 and $5 \mathrm{hPa}$ and neutral to positive above. After the transition, during 1983-1989, wind shear between 20 and $50 \mathrm{hPa}$ is also increased. Figure $7 \mathrm{~b}$ illustrates that thermal wind balance generally gives a good approximation to the wind shear. However, during the period 1983-1989 and, to a lesser degree, afterwards, thermal wind balance is weaker between 5 and $2 \mathrm{hPa}$. A further analysis based on 1-year instead of 7 -year means (not shown) can demonstrate that this feature does not have a QBO signal itself.

The Figs. 5-7 shows a number of features especially in the region above $10 \mathrm{hPa}$, and differences between the initial and later period of the reanalysis, as expected from the composites.

\section{Discussion of the observed trends and variations}

Possible Explanations for features of interannual variability in the ERA-40 reanalysis fall in two groups:

1. Features of the real atmosphere 

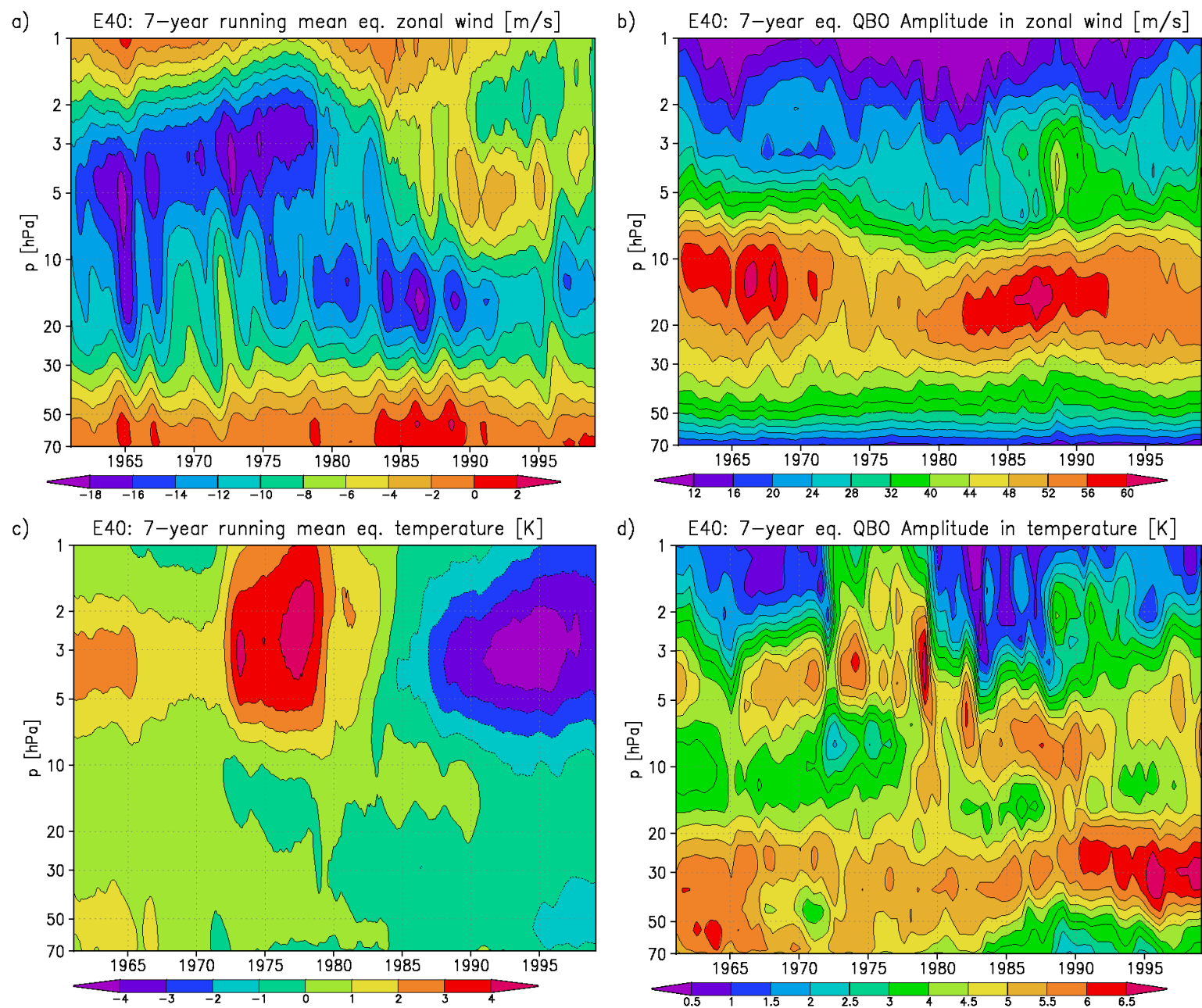

Fig. 5. (a) 7-year running mean of zonal mean zonal wind at the equator, in $\mathrm{m} / \mathrm{s}$. (b) 7-year running mean estimate of the QBO amplitude over the course of the record, in m/s. (c) As in (a), but for temperature anomaly, in K. (d) As in (b), but for temperature, in K.

2. Features due to shortcomings of the observing and analysis system

In the first group, the QBO is most important in the tropical stratosphere. It is variable in period and also shows variability in amplitude, as Fig. 5b suggests.

Since the QBO is a dynamically driven phenomenenon, it can be expected that amplitude changes are connected to other atmospheric processes, e.g. via strength of tropospheric waves and their propagation conditions. These are, however, fairly complex and likely nonlinear, and their discussion is therefore beyond the scope of this work, also considering the sparsity of early data and changes to the observing system later.

A closer investigation of the increased QBO amplitude at the end of the 1980s displayed in Fig. 5b reveals that a strong QBO phase in 1986/1987 that enters the seven year window is responsible for the increase. A more smooth decrease of the amplitude follows in the 1990s and another rapid increase occurs in the last year of the record but can not be identified very clearly in Fig. 5b. The similarity of the two jumps suggests that they are not due to the observing system but either a product of model dynamics (not restricted by observations) or a common property of the climate system. A potential mechanism would be the alignment of annual and quasibiennial cycles in a certain constellation affecting the amplitudes. The data record is however too short to prove such a connection. Instead, one could argue that the 1986/1987 jump is due to other explanations to be discussed below. On the other hand, increased QBO amplitudes after 1985 coincide with the colder period in the temperature field of Fig. $5 \mathrm{c}$.

The annual cycle and the semi-annual oscillation are the other two important modes of variability in the tropical stratosphere. They are not represented in Fig. 5a, but, clearly, changes in the annual or semiannual cycle will affect the annual mean. In fact, it is found that the monthly climatological values of zonal wind in the earlier and later period differ. 

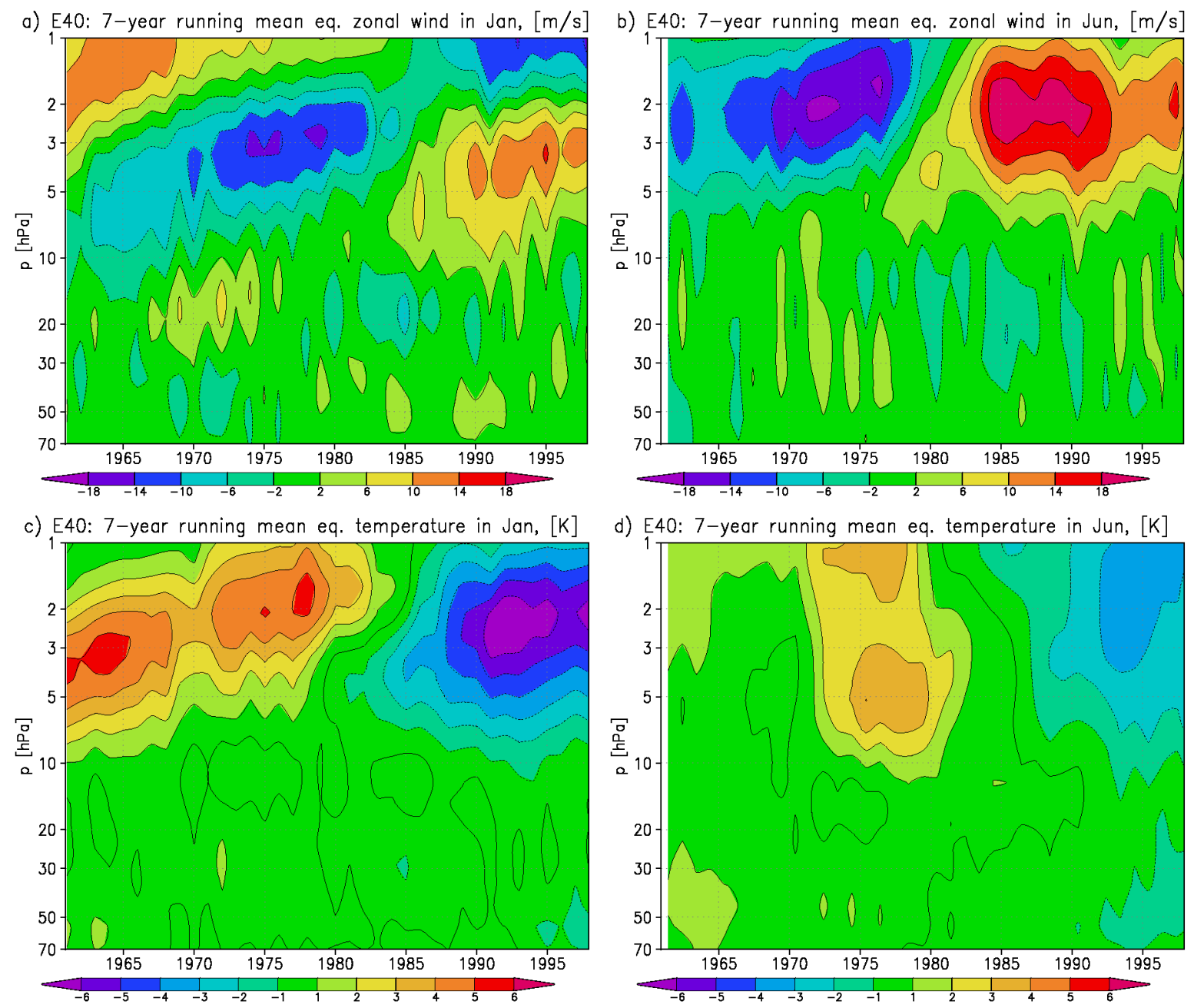

Fig. 6. (a) 7-year running climatology of zonal mean zonal wind anomaly in January, in $\mathrm{m} / \mathrm{s}$. (b) As in (a), but for June. (c) As in (a), but for temperature anomaly, in K. (d) As in (c), but for June.

In an earlier study, Crooks and Gray (2005) discussed the effect of ENSO and volcanic eruptions on the climate of the stratosphere in ERA-40. They found easterlyward shifts in annual mean zonal wind of up to $5 \mathrm{~m} / \mathrm{s}$ per standard deviation change in stratospheric optical depth between 5 and $10 \mathrm{hPa}$ after major volcanic eruptions. However, Fig. 5 does not show more easterly winds for the years following the eruptions of Agung (1963/1964), El Chichon (1984) and Mt. Pinatubo (1993). Similarly, an impact of ENSO on upper stratospheric winds can not be shown in this study, also because time resolution is too small. We do not find signatures of the 11-year solar cycle, as there are too many short term variations superimposed to a potential cycle. ERA-40 may actually not cover such effects if they originate higher up in the atmosphere, as the model top is at $0.1 \mathrm{hPa}$.

Finally, a general trend in climate conditions will also affect the conditions in the upper stratosphere. In fact, a strato- spheric cooling trend in ERA-40 as it is observed in Fig. 5c has previously been reported by Santer et al. (2004) and been related to a global warming trend in the troposphere. On the other hand, a trend towards more westerly wind shear as found in Fig. $7 \mathrm{c}$ above $5 \mathrm{hPa}$ would mean by thermal wind balance a relative warming of the tropical stratosphere with respect to the subtropics and thus support that the equatorial region is not as susceptible to the cooling effect of climate change as the subtropics are. On the other hand, shrinking of the meridional extent of the QBO as found by (Huesmann and Hitchman, 2004) in the NCEP-reanalysis, would have the same effect.

The second group of possible explanations is similarly diverse. Table 1 lists the events discussed here. First of all, the number and kind of observations varies over the course of the record. The lack of data in the assimilation in the presatellite era allows the model to develop its own dynamics 
Table 1. Possible sources for anomalies and inconsistencies in the ERA-40 reanalysis system that are discussed in the text.

\begin{tabular}{lll}
\hline Year & Month & Event \\
\hline 1957 & Sep & Start of ERA-40, stream \#2 \\
1972 & & Start satellite temperature assimilation from VTPR \\
1972 & June & Stream \#2.5 \\
1973 & & Start station ID problem with radiosondes \\
1973 & April & Stream \#3 \\
1977 & & End station ID problem with radiosondes \\
1978 & & End of VTPR temperature assimilation \\
1979 & & Start satellite observations from TOVS \\
1979 & & Start ozone assimilation from from TOMS/SBUV \\
1982 & & Start use of METEOSAT cloud motion winds \\
1985 & May & Stream \#5 \\
1986 & June & Stream \#4 \\
1987 & & Start of SSM/I satellite observations \\
1988 & & End use of METEOSAT cloud motion winds \\
1989 & Feb & Stream \#1 \\
2002 & Aug & End of ERA-40 \\
\hline
\end{tabular}

(Sterl, 2004; Uppala et al., 2005). Satellites deliver valuable information on the state of the upper stratosphere which is not reached by radiosondes particularly after 1979, when TOVS data is assimilated. Considering our results, e.g. the monthly anomalies in Fig. 6b, it seems likely that the introduction of extensive satellite data around 1979 caused much of the diagnosed difference between the two halves of ERA40. However, it is not clear why this change should be delayed by up to six years.

Furthermore, Andrae et al. (2004) discuss the corrections that were applied to the radiosonde temperature data from 1980 on. While corrections were generally small, a stronger correction at one of the relatively few equatorial stations could have a strong effect. For the period 1973-1977, these authors also report problems with inconsistent station IDs that led to the same data being used twice. Besides this, their Fig. 1 shows a drop in the number of $30 \mathrm{hPa}$ radiosonde observations after 1978 .

The changes can not only be due to more accurate measurements, but resolution effects can also play a role. Huesmann and Hitchman (2004) proposed that satellite measurements will underestimate the temperature QBO amplitude because of lacking vertical resolution.

The warm period observed in Fig. 5c during the 1970s is deceiving - we found that it is due to a strong warm anomaly of up to $15 \mathrm{~K}$ in the years 1975 and 1976 that is smoothed by our averaging algorithm to give a $4 \mathrm{~K}$ anomaly lasting from 1972 to 1979 . A similar anomaly also shows up as a bias in ERA-40 first guess global mean temperature versus radiosonde data as reported by Andrae et al. (2004) in their Fig. 1, although that one, at 30 and $250 \mathrm{hPa}$, is much smaller, below $1 \mathrm{~K}$ in amplitude. Gleisner et al. (2005) report anomalous upper tropospheric thickness for the same period. There is reason to believe that this anomaly is due to a problem with the assimilation system during the period, that just is much more severe in the upper stratosphere as the model is not restricted by sonde observations there. The ERA-40 webpage reports an increased error rate in temperature data from the VTPR instrument on NOAA4 satellite at the end of its service in 1976, also mentioned by Santer et al. (2004) and van Noije et al. (2006) as a potential error source.

The deviation from thermal wind balance found for 19831988 coincides with the period during which METEOSAT cloud motion winds were assimilated. While a direct effect of the tropospheric winds on those in the upper stratosphere is impossible, the wind assimilation may have affected resolved waves that were damped in the stratosphere and thereby transferred their momentum.

The ERA-40 reanalysis was computed in six streams as shown in the online documentation (http://www.ecmwf.int/ research/era/). The transitions among streams, are also potential sources for changes in the reanalysis data set. In particular, the transitons of streams \#3 to \#5 (May 1985), \#5 to \#4 (June 1986) and \#4 to \#1 (February 1989) coincide with some of the anomalies in Fig. 5. During stream \#4, zonal winds were particularly easterly between 10 and $20 \mathrm{hPa}$, while they became more and more westerly above $7 \mathrm{hPa}$. The start of stream \#4 also marks the beginning of the cooling phase in Fig. 5c.

\section{Conclusions}

The variability of atmospheric conditions of the equatorial upper stratosphere can not be fully understood from the ERA-40 reanalysis record. The ERA-40 system produces 
a)

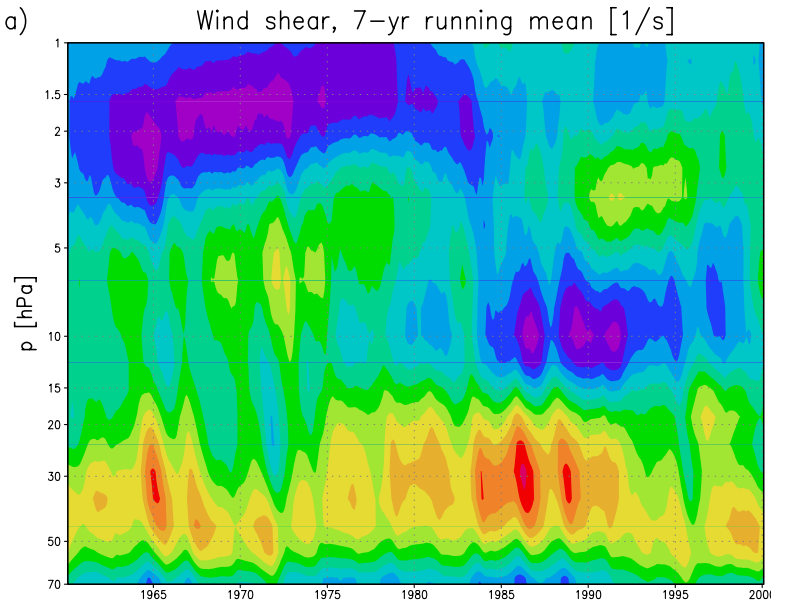

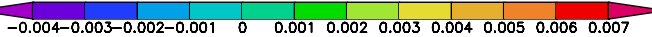

b) Actual-thermal wind shear, $7-y r$ running mean $[1 / \mathrm{s}]$

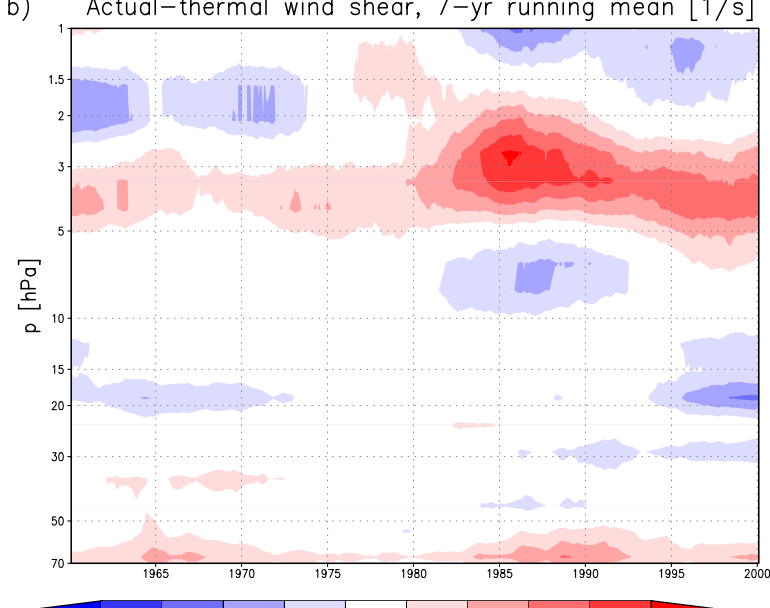

Fig. 7. (a) 7-year running mean of vertical zonal mean zonal wind shear at the Equator, in 1/s. (b) Difference between (a) and 7-year running mean thermal wind shear, in $1 / \mathrm{s}$.

a periodic pattern of the quasi-biennial oscillation which is consistent with the better-observed middle and lower stratospheric QBO from radiosonde observations. However, this study reveales some curiosities - in particular, the earlier part (1960-1979) of ERA-40 shows a QBO in the upper stratosphere that is distinctly different from the one in the later part (1980-1999). Most prominently, a westerly shift of up to $12 \mathrm{~m} / \mathrm{s}$ is observed in the zonal wind between the two sections. No obvious reason for this was found.

Because few or no observations are available for the upper stratosphere region, especially in the earlier years, it is not clear whether our findings are artifacts of the ERA-40 reanalysis system or whether they represent the real state of the atmosphere. A couple of shifts in upper stratospheric conditions can be related to problems with or changes of the reanalysis system, such as the warm stratosphere in 1975/1976, or the introduction of satellites in 1979.

However, for the long term differences, no satisfying explanation could be given. If we assume the dynamics of the model is working well, reproducing the climate several levels above where observations were available in the pre-satellite period, our work indicates there is substantial variability on time scales longer than the QBO period. On the other hand, there are some caveats with the reanalysis related to data quality, quantity or assimilation, and a more careful review of the data sources used and the assimilation system is required, which is beyond the scope of this work.

Anyway, there is reason to believe that the later portion of the ERA-40 displays the more realistic description of tropical zonal winds and the QBO, as it is based on more and likely higher-quality observations, including detailed satellite data since the late 1970 s.

Given these findings, care should be taken when using the ERA-40 reanalysis as a reference, e.g. for model development and validation purposes, where winds in the tropical upper stratosphere play a role. Another outcome of this study is that reliable long term data records from observations are crucial for any statements on interannual atmospheric variability in this region of the atmosphere.

Acknowledgements. This work was supported by the European Community project 505390 SCOUT-O3. The authors thank E. Roeckner for helpful comments. In particular, we would like to thank the two external reviewers for their comments and ideas which inspired valuable additions to this article.

Edited by: K. Hamilton

\section{References}

Andrae, U., Sokka, N., and Onogi, K.: The radiosonde temperature bias corrections used in ERA-40, ERA-40 Project Report Series, 15, 1-37, 2004.

Baldwin, M. P., Gray, L. J., Dunkerton, T. J., Hamilton, K., Haynes, P. H., Randel, W. J., Holton, J. R., Alexander, M. J., Hirota, I., Horinouchi, T., Jones, D. B. A., Kinnersley, J. S., Marquardt, C., Sato, K., and Takahashi, M.: The Quasi-Biennial Oscillation, Rev. Geophys., 39, 179-229, 2001.

Baldwin, M. P. and Gray, L. J.: Tropical stratosphere zonal winds in ECMWF ERA-40 reanalysis, rocketsonde data, and rawinsonde data, Geophys. Res. Lett., 32, L09806, doi:10.1029/ 2004GL022328, 2005.

Bengtsson, L., Hodges, K. I., and Hagemann, S.: Sensitivity of the ERA40 reanalysis to the observing system: determination of the global atmospheric circulation from reduced observations, Tellus, 56A, 456-471, 2004.

Crooks, S. A. and Gray, L. J.: Characterization of the 11-year solar signal using a multiple regression analysis of the ERA-40 dataset, J. of Climate, 18, 996-1015, 2005.

Giorgetta, M. A., Manzini, E., Roeckner, E., Esch, M., and Bengtsson, L.: Climatology and Forcing of the Quasi-Biennial Oscil- 
lation in the MAECHAM5 Model, J. Climate, 19, 3882-3901, doi:10.1175/JCLI3830.1, 2006.

Gleisner, H., Thejll, P., Stendel, M., Kaas, E., and Machenhauer, B.: Solar signals in tropospheric re-analysis data: Comparing NCEP/NCAR and ERA40, J. of Atmos. and Sol.-Terr. Phys., 67, 785-791, 2005.

Holton, J. R. and Lindzen, R. S.: An updated theory for the quasibiennial cycle of the tropical stratosphere, J. Atmos. Sci., 29, 1076-1080, 1972.

Huesmann, A. S. and Hitchman, M. H.: The 1978 shift in the NCEP reanalysis stratospheric quasi-biennial oscillation, Geophys. Res. Lett., 30, 1048, doi:10.1029/2002GL016323, 2004.

Pascoe, C. L., Gray, L. J., Crooks, S. A., Juckes, M. N., and Baldwin, M. P.: The quasi-biennial oscillation: Analysis using ERA-40 data, J. Geophys. Res., 110, D08105, doi:10.1029/ 2004JD004941, 2005.

Randel, W., Udelhofen, P., Fleming, E., Geller, M., Gelman, M., Hamilton, K., Karoly, D., Ortland, D., Pawson, S., Swinbank, R., Wu, F., Baldwin, M., Chanin, M. L., Keckhut, P., Labitzke, K., Simmons, E. R. A., and Wu, D.: The SPARC Intercomparison of middle-atmospheric climatologies, J. Climate, 17, 986-1003, 2004.

Santer, B. D., Wigley, T. M. L., Simmons, A. J., Kallberg, P. W., Kelly, G. A., Uppala, S. M., Ammann, C., Boyle, J. S., Brüggemann, W., Doutriaux, C., Fiorino, M., Mears, C., Meehl, G. A., Sausen, R., Taylor, K. E., Washington, W. M., Wehner, M. F., and Wentz, F. J.: Identification of anthropogenic climate change using a second-generation reanalysis, J. Geophys. Res., 109, D21104, doi:10.1029/2004JD005075, 2004.
Sterl, A.: On the (In)Homogeneity of Reanalysis Products, J. Climate, 17, 3866-3873, 2004.

Takahashi, M.: Simulation of the stratospheric quasi-biennial oscillation using a general circulation model, Geophys. Res. Lett., 23, 661-664, 1996.

Uppala, S., Kallberg, P., Hernandez, A., Saarinen, S., Fiorino, M., Li, X., Onogi, K., Sokka, N., Andrae, U., and Bechtold, V. D. C.: ERA-40: ECMWF 45-year reanalysis of the global atmosphere and surface conditions 1957-2002, ECMWF Newsletter, 101, 221, 2004.

Uppala, S., Kallberg, P., Simmons, A. J., Andrae, U., Bechtold, V. D. C., Fiorino, M., Gibson, J. K., Haseler, J., Hernandez, A., Kelly, G. A., Li, X., Onogi, K., Saarinen, S., Sokka, N., Allan, R. P., Andersson, E., Arpe, K., Balmaseda, M. A., Beljaars, A. C. M., van de Berg, L., Bidlot, J., Bormann, N., Caires, S., Chevallier, F., Dethof, A., Dragosavac, M., Fisher, M., Fuentes, M., Hagemann, S., Holm, E., Hoskins, B. J., Isaksen, L., Janssen, P. A. E. M., Jenne, R., McNally, A. P., Mahfouf, J. F., Morcrette, J. J., Rayner, N. A., Saunders, R. W., Simon, P., Sterl, A., Trenberth, K. E., Untch, A., Vasiljevic, D., Viterbo, P., and Woollen, J.: The ERA-40 re-analysis, Q. J. R. Meteorol. Soc., 131, 29613012, 2005.

van Noije, T. P. C., Segers, A. J., and van Velthoven, P. F. J.: Time series of the stratosphere-troposphere exchange of ozone simulated with reanalyzed and operational forecast data, J. Geophys. Res., 111, D03301, doi:10.1029/2005JD006081, 2006. 